\title{
Eco-efficient based logistics network design in hybrid manufacturing/ remanufacturing system in low-carbon economy
}

\author{
Yacan Wang ${ }^{1}$, Xiaoxia Zhu ${ }^{2}$, Tao Lu ${ }^{1}$, Ananda S Jeeva ${ }^{3}$ \\ ${ }^{1}$ Beijing Jiaotong University, School Of Economics and Management (China) \\ ${ }^{2}$ School of Sciences, Hebei University of Science And Technology (China) \\ ${ }^{3}$ School of Information Systems, Curtin University (Australia) \\ yacan.wang@gmail.com.Zhuxiaoxia66@126.com.07224015@,bjtu.edu.cn._A.Jeeva@,curtin.edu.au
}

Received August 2012

Accepted February 2013

\section{Abstract:}

Purpose: Low-carbon economy requires the pursuit of eco-efficiency, which is a win-win situation between economic and environmental efficiency. In this paper the question of trading off the economic and environmental effects embodied in eco-efficiency in the hybrid manufacturing/remanufacturing logistics network design in the context of low-carbon economy is examined.

Design/methodology/approach: A multi-objective mixed integer linear programming model to find the optimal facility locations and materials flow allocation is established. In the objective function, three minimum targets are set: economic cost, $\mathrm{CO}_{2}$ emission and waste generation. Through an iterative algorithm, the Pareto Boundary of the problem is obtained.

Findings: The results of numeric study show that in order to achieve a Pareto improvement over an original system, three of the critical rates (i.e. return rate, recovery rate, and cost substitute rate) should be increased.

Practical implications: To meet the need of low-carbon dioxide, an iso- $\mathrm{CO}_{2}$ emission curve in which decision makers have a series of optimal choices with the same $\mathrm{CO}_{2}$ emission but different cost and waste generation is plotted. Each choice may have different network design 
but all of these are Pareto optimal solutions, which provide a comprehensive evaluation of both economics and ecology for the decision making.

Originality/value: This research chooses carbon emission as one of the three objective functions and uses Pareto sets to analyze how to balance profitability and environmental impacts in designing remanufacturing closed-loop supply chain in the context of low-carbon economy.

Keywords: hybrid manufacturing/remanufacturing system, tradeoff, pareto improvement, logistic network design, low-carbon economy, eco-efficiency

\section{Introduction}

Remanufacturing supply chain consists of not only the traditional forward logistics network for manufacturing and distribution but also the reverse logistics supply chain logistics network for remanufacturing, which is a typical closed-loop manufacturing/remanufacturing hybrid system (Ma \& Dai, 2005). During the design of hybrid manufactured/remanufacturing logistics network, economic efficient and environmental efficiency have been treated as two separated goals for long, and they haven't been integrated with each other, which is against the interest of low-carbon economy. Low-carbon economy represents the lowest carbon emission, environmental impact and economic cost during the development (Fang, 2010). In essence, it is the pursuit of eco-efficiency, which is a win-win situation between economic and environmental efficiency ( $\mathrm{Xu}, 2011)$. In regard to this, the logistics network design of ecoefficient based hybrid manufacturing/remanufacturing system aiming at both cost optimization and energy conservation \& emission reduction has been the pressing task.

Increasing attentions have been paid to examine the integrated logistics network design in hybrid remanufacturing system, but only adopts single objective, normally minimum cost (Ma \& Dai, 2005; Xie, Zhao \& Ren, 2008; Francasa \& Minner, 2009; Easwarana \& Üsterb, 2010). Among the following eco-efficient logistics network design research, Bloemhof-Ruwaard (1996) examines the logistics network design of pulp and paper industry by adopting life cycle analysis (LCA) to achieve an eco-efficiency index for every process during paper production. But this network is only a recycling type, which is far less simple than hybrid remanufacturing system. Moreover, he then adopts the index to optimize logistics network, but in his model, environmental impact is the only objective function. (Neto Fronta, Bloemhof-Ruwaard, Van Nunen and Van Heck (2008) develop a model adopting dual-objective programming to optimize economic cost and environmental impact simultaneously. Bloemhof and Neto's research adopt the same method in analyzing environmental impact, i.e., global warming, 
toxic gas and solid waste. Neto Fronta, Walther, Bloemhof-Ruwaard, van Nunen and Spengler (2009) and Krikke, Bloemhof-Ruwaard and Wassenhove (2003) model adopts three objectives: cost, energy consumption and solid waste. Neto focuses more on the relationship between solid waste and energy consumption while Krikkle et al. integrates product design with the design of logistics network and has proved that appropriate product design can enhance the efficiency of logistics network. This research associates carbon emission to our objective function and uses Pareto sets to analyze how to balance profitability and environmental impacts in designing remanufacturing closed-loop supply chain in the context of low-carbon economy.

The trade-off relationships exist among the objectives in this paper (profitability, $\mathrm{CO} 2$ emission and solid waste discharge), i.e., it is impossible to realize maximum profitability, optimized energy consumption and solid waste discharge simultaneously (Neto et al., 2008; Neto et al., 2009). The idea of Pareto-optimal is adopted to search for the best solution to avoid negative influence on other solutions and all trade-offs between the logistic network cost and its environmental impact. To obtain Pareto boundary, a tri-objective mathematical programming is set up. Numeric examples are used to analyze how to realize Pareto improvement, the improvement on planet and profit simultaneously in designing logistics network. To meet the need of low-carbon economy, this paper attempts to search for the solutions for manufacturing companies to comprise both business and the environment given a certain level of carbon emission constraints.

\section{Mathematical Model}

\subsection{Description of the Problem}

We use mixed-integer linear programming (MILP) to design logistics network in manufacturing and remanufacturing hybrid system. Manufacturing and remanufacturing hybrid system means the producer produces new products while reproduces the end-of-life ones. The designed network consists of factory, distribution center, consumption area, recycling center, and solid waste disposal location. Among them, products collected can be divided into recoverable for remanufacturing and unrecoverable for disposal. This model contributes to determine the optimal locations of factory, distribution center, recycling center and distribution/recycling center, as well as the allocations of both forward and reverse material flows in the closed-loop supply chain.

A sample manufacturing/remanufacturing logistics network is assumed as follows: there are $M$ potential factories, which can manufacture and remanufacture; J potential recycling center, which check and categorize the collected products. After checking and categorizing, the recoverable will be sent to factories for remanufacturing. After remanufacturing, the products will be sold in I potential distribution center and the unrecoverable products will be dealt in the 
disposal facility. The Logistics network topology structure is illustrated in Figure 1. We make advantage of mathematical model, take minimum logistic cost, carbon emission and solid waste as optimization objectives and work out the best solution for location for factory, distribution center, collection point and the materials flow allocation.

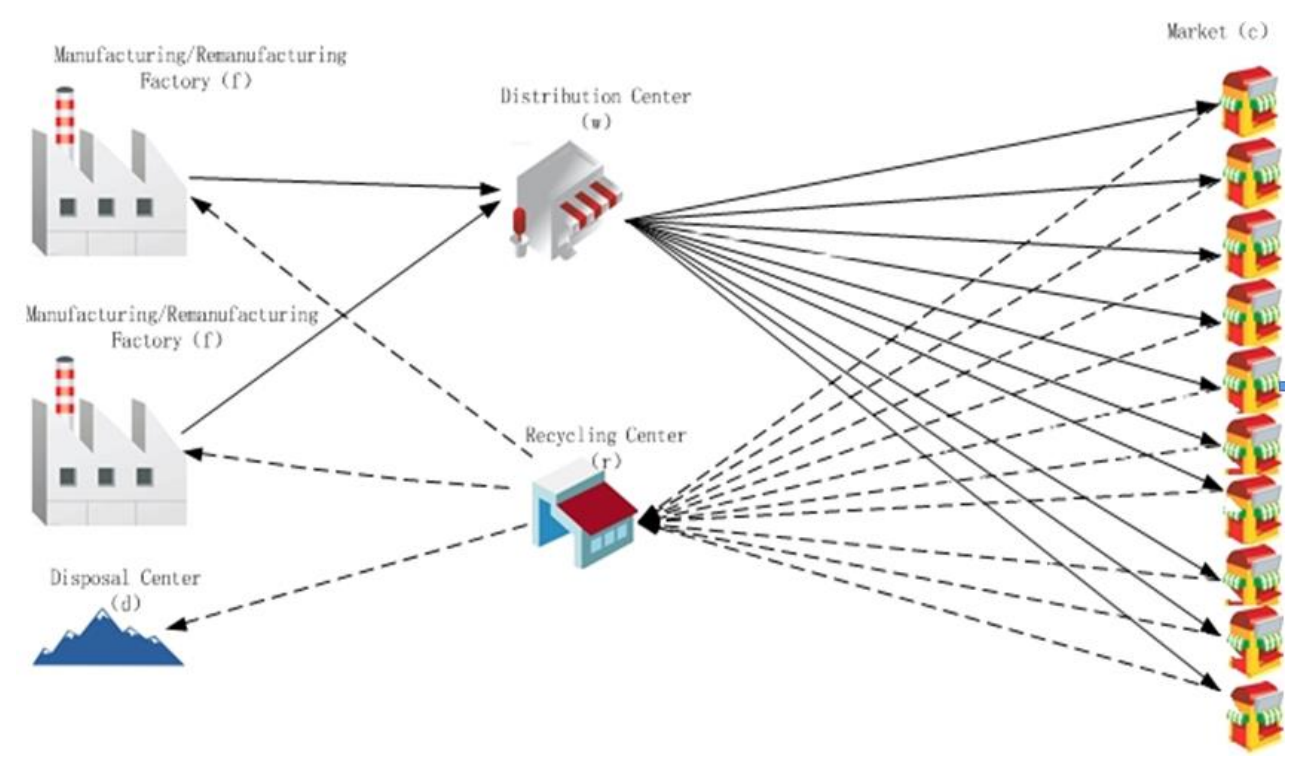

Figure1. Logistics network topology structure of the model

\subsection{Assumptions}

First we concern the basic assumptions in this model, as those in Table 1

\begin{tabular}{|l|l|}
\hline No. & Assumptions \\
\hline 1 & $\begin{array}{l}\text { Factories can both manufacture and remanufacture and those products } \\
\text { can all meet the market demand via distribution center. }\end{array}$ \\
\hline 2 & $\begin{array}{l}\text { Remanufacturing the collected products can save cost, and we believe } \\
\text { the cost saved and products recycled are in positive relation. }\end{array}$ \\
\hline 3 & $\begin{array}{l}\text { Products collection is calculated by areas and is in positive relation to } \\
\text { the particular consumption and return rate is certain and known. } \\
\text { Products can be remanufactured in the factories after checking by the } \\
\text { collection point. }\end{array}$ \\
\hline 4 & $\begin{array}{l}\text { We assume the ratio of remanufacturing to all collected products is } \\
\text { exogenous. }\end{array}$ \\
\hline
\end{tabular}

Table 1. Assumed conditions of the model

The notations are shown in Appendix 1 (table 5), which explicitly introduces the decision variables (table 6) and parameters (table 7) in the model.

\subsection{Formulation}

To cater for the need of low-carbon economy, three optimization goals are set in the model: 1 . Minimum total cost. This cost is the sum cost throughout one product's life cycle, including raw material supply, product design, spare parts production and assembly, distribution, collection, dismantling, remanufacturing, and resale; 2. Minimum environmental impact. 
Considering the difficulty in fetching all LCA data of the products, it becomes regular practice to use simplified indicators instead of doing a full LCA to lower data requirements in mathematic modeling (Sasse, Karl \& Renz, 1999; Umeda, Nonomura \& Tomiyama, 2000). In this paper, we adopt waste generation and carbon-dioxide emission for an approximation to evaluate environmental impact. Waste generation refers to all waste in need of treatment (including incineration treatment) generated throughout this close-loop supply chain. Carbon emission refers to all carbon emitted throughout this close-loop supply chain. The optimization objectives are illustrated in Figure 2.

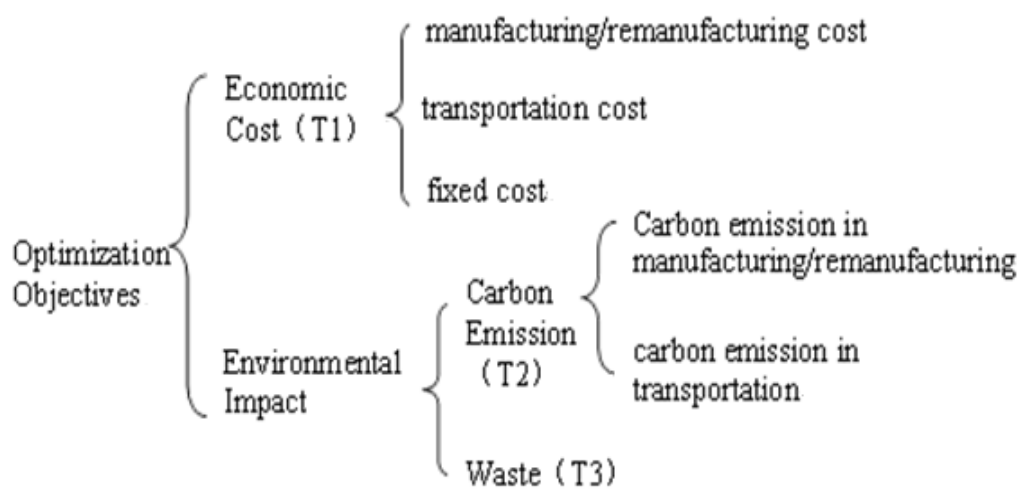

Figure 2. Optimization objectives of the model

Optimization objective

The first optimization objective is minimum economic cost:

$$
\min T_{1}=F C+T C+M C
$$

which includes the fixed costs of setting up factories, distribution centers and recycling center

$$
F C=\sum_{m} F_{m}^{f} Y_{m}^{f}+\sum_{i} Y_{i}^{w} F_{i}^{w}+\sum_{j} Y_{j}^{r} F_{j}^{r}
$$

Transportation cost consists of that in forward logistics (from factory to distribution center) and reverse logistics (from market to recycling center and then to factory and disposal facility).

$$
T C=\sum_{i} \sum_{m} C_{m i} X_{m i}+\sum_{i} \sum_{c} C_{i c} X_{i c}+\sum_{c} \sum_{j} C_{c j} X_{c j}+\sum_{j} \sum_{m} C_{j m} X_{j m}+\sum_{j} \sum_{d} C_{j d} X_{j d}
$$

Cost of manufacturing/remanufacturing: cost of manufacturing minuses cost saved by remanufacturing. 


$$
M C=\sum_{m} \sum_{i} C_{p} X_{m i}-\sum_{j} \sum_{m} C_{r} X_{j m}
$$

The second optimization objective is minimum carbon emission

$$
\min T_{2}=T E+M E
$$

The calculation of the carbon emission during transportation is similar to that in (1)

$$
T E=\sum_{i} \sum_{m} E_{m i} X_{m i}+\sum_{i} \sum_{c} E_{i c} X_{i c}+\sum_{c} \sum_{j} E_{c j} X_{c j}+\sum_{j} \sum_{m} E_{j m} X_{j m}+\sum_{j} \sum_{d} E_{j d} X_{j d}
$$

Carbon emission during manufacturing/remanufacturing: carbon emission of manufacturing minuses carbon emission saved by remanufacturing.

$$
M E=\sum_{m} \sum_{i} E_{p} X_{m i}-\sum_{j} \sum_{m} E_{r} X_{j m}
$$

The last objective is minimum waste discharge

$$
\min T_{3}=\sum_{j}\left[\sum_{c} X_{c j}-\left(\sum_{m} X_{j m}+\sum_{d} X_{j d}\right)\right]
$$

According to WEEE, the quantity of waste equals to the quantity of the discarded products received by the collection point minuses the amount of products recovered (Neto et al., 2009). In this paper, collection point includes the factory and disposal facility. The factory reproduces the end-of-life products and disposal facilities recycle the discarded ones.

Constraints

$$
\begin{gathered}
X_{m i}, X_{i c}, X_{c j} \ldots \geq 0 \\
Y_{m}^{f}, Y_{i}^{w}, Y_{j}^{r}=0,1
\end{gathered}
$$

(4) represents the materials flow allocation of each route is nonnegative;

(5) represents the location decision variable is constrained by $0-1.1$ represents the correspondent facility is under construction and 0 represents the opposite.

$$
\begin{gathered}
\sum_{i} X_{m i} \leq A_{m}^{f} Y_{m}^{f}, \forall m \\
\sum_{c} X_{i c} \leq A_{i}^{w} Y_{i}^{w}, \forall i
\end{gathered}
$$




$$
\sum_{c} X_{c j} \leq A_{j}^{r} Y_{j}^{r}, \forall j
$$

(6) - (8) represent the capacity constraints of factory, distribution center and collection point respectively

$$
\sum_{i} X_{i c}=D_{c}, \forall c
$$

(9) represents products delivered from the distribution center to the market must meet its demand

$$
\sum_{m} X_{m i}=\sum_{c} X_{i c}, \forall i
$$

(10) represents the materials flow balance among the distribution centers

$$
\delta_{c} \sum_{i} X_{i c}=\sum_{j} X_{c j}, \forall c
$$

(11) represents the products collected from the market by the recycling center equals to the amount of products sold in the market times to return rate

$$
\begin{gathered}
(1-\beta) \sum_{c} X_{c j} \geq \sum_{d} X_{j d}, \forall j \\
\beta \sum_{c} X_{c j}=\sum_{m} X_{j m}, \forall j
\end{gathered}
$$

(12) and (13) represent after checking and categorizing in the recycling center, products are delivered to disposal facility and factory for reproducing.

To sum up, a model for a single product in a single loop with limited capacity in a manufacturing/remanufacturing hybrid logistics network is set up. The optimization objectives consider not only the optimal cost but also the minimum waste generation and energy consumption. On choosing the decision variables represent, this model also concerns both the logistics facilities' locations and materials flow allocation.

\section{Algorithm and Numeric Study}

The numeric study is done using an example of refrigerator industry. We randomly generated 5 potential factories, 6 potential distribution centers and recycling centers, 8 markets and the coordinates $(\mathrm{km})$ of 4 disposal facilities, as depicted in table 2. Take refrigerator as example, each refrigerator is about 65 kilograms and the transportation cost is 2 Yuan/ton each 
kilometer. Transportation consumes 0.015 liter/ton each kilometer. The manufacturing cost per unit is 300 Yuan, and it consumes 1 kilowatt. According to $\mathrm{CO}_{2}$ emission index, $2.69 \mathrm{~kg}$ $\mathrm{CO}_{2}$ emits for every liter of gasoline and $0.785 \mathrm{~kg}$ for each kilowatt. The fixed cost of facilities is illustrated in table 3 . There are 100 refrigerators demanded for each market, the capacity of each factory is 500 and the maximum capacity for distribution center and recycling center is 300 and 200 respectively.

\begin{tabular}{|l|l|l|l|l|l|l|l|l|l|l|}
\hline \multicolumn{2}{|c|}{ Disposal Facility } & \multicolumn{2}{c|}{ Factory } & \multicolumn{2}{c|}{ Distribution Center } & Recycling Center & \multicolumn{2}{c|}{ Market } \\
\hline $\mathrm{x}$ & $\mathrm{y}$ & $\mathrm{x}$ & $\mathrm{y}$ & $\mathrm{x}$ & $\mathrm{x}$ & $\mathrm{y}$ & $\mathrm{x}$ & $\mathrm{x}$ & $\mathrm{y}$ \\
\hline 75.05 & 80.30 & 41.99 & 19.39 & 65.55 & 59.47 & 70.36 & 96.16 & 60.20 & 85.80 \\
\hline 74.00 & 8.39 & 75.37 & 90.48 & 39.19 & 56.57 & 48.50 & 5.89 & 25.36 & 33.58 \\
\hline 43.19 & 94.55 & 79.39 & 56.92 & 62.73 & 71.65 & 11.46 & 36.03 & 87.35 & 68.02 \\
\hline 63.43 & 91.59 & 92.00 & 63.18 & 69.91 & 51.13 & 66.49 & 54.85 & 51.34 & 5.34 \\
\hline & & 84.47 & 23.44 & 39.72 & 77.64 & 36.54 & 26.18 & 73.27 & 35.67 \\
\hline & & & & 41.36 & 48.93 & 14.00 & 59.73 & 42.22 & 49.83 \\
\hline & & & & & & & & 96.14 & 43.44 \\
\hline & & & & & & & & 7.21 & 56.25 \\
\hline
\end{tabular}

Table 2. Potential Locations' Coordinates

\begin{tabular}{|c|c|c|c|c|c|}
\hline \multicolumn{7}{|c|}{ Fixed cost of factories (RMB) } \\
\hline $\mathrm{f1}$ & $\mathrm{f} 2$ & $\mathrm{f3}$ & $\mathrm{f4}$ & \multicolumn{2}{c|}{$\mathrm{f5}$} \\
\hline 300000 & 400000 & 300000 & 300000 & 300000 \\
\hline $\mathrm{w} 1$ & Fixed cost of distribution centres (RMB) \\
\hline 30000 & $\mathrm{w} 2$ & $\mathrm{w} 3$ & $\mathrm{w} 4$ & $\mathrm{w5}$ & w6 \\
\hline \multicolumn{7}{|c|}{ Fixed cost of recycling centre (RMB) } \\
\hline r1 & r2 & r3 & r4 & r5 & r6 \\
\hline 10000 & 10000 & 10000 & 10000 & 10000 & 10000 \\
\hline
\end{tabular}

Table 3. The Fixed Cost of Facilities

In the following two sections, relevant algorithms and computational results are given

\subsection{Pareto boundary on different parameter conditions}

To solve the mixed multi-objective integer programming model in this paper, we use comprehensive solvers for mixed integer programming, like cplex and Lingo. However, to achieve the Pareto sets of this model, a reasonable iterative algorithm should be designed. For there are clear upper and lower bounds for objective function (3), we will gradually relax objective function (3) and comprise that with objective (1) and (2) and finally work it out after weighting. The algorithm step is shown below:

Step 1. Compute, $\bar{T}_{3}:=\max T_{3}, \underline{T}_{3}:=\min T_{3}$. Set $\varepsilon:=\left(\bar{T}_{3}-\underline{T}_{3}\right) / n$, Set $k:=0$;

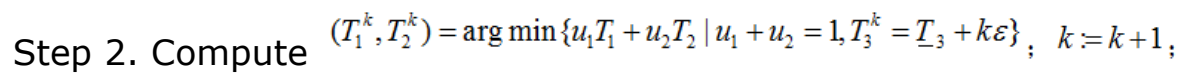


Step 3. If $k=n+1$, end and output $T^{*}=\left\{\left(T_{1}^{k}, T_{2}^{k}, T_{3}^{k}\right) \mid k=0,1, \ldots, n\right\}$; Otherwise, go back to Step 2.

By examining the tendency of the boundaries in Figure 3, we can have the following observations (return rate $=0.8$, recovery rate $=0.5$ ): (1) there is trade-off relation between carbon emission and waste generation; (2) there is also trade-off relation between economic cost and waste generation. The reasons to explain these two relations are twofold: on the one hand, the separating layout of remanufacturing center calls for a larger number of vehicles. When there is a certain quantity of discarded products to be dealt with, there needs more vehicles and longer distances to deliver them to different recovery center comparing with direct delivery to disposal facilities; on the other hand, for the landfill disposal is replaced by remanufacturing, remanufacturing also consumes more energy. Therefore, when recovery deals with more discarded products and the waste generation decreases, the increase in vehicles and distance lead to more energy consumption in transportation and recovering and this explains the trade-off relation between carbon emission and waste generation. In addition, freight and management cost also increase and the increasing consumption in energy, facilities, equipment, human resources lead to the rise of operation cost, and this explains the trade-off relation between economic cost and waste generation.
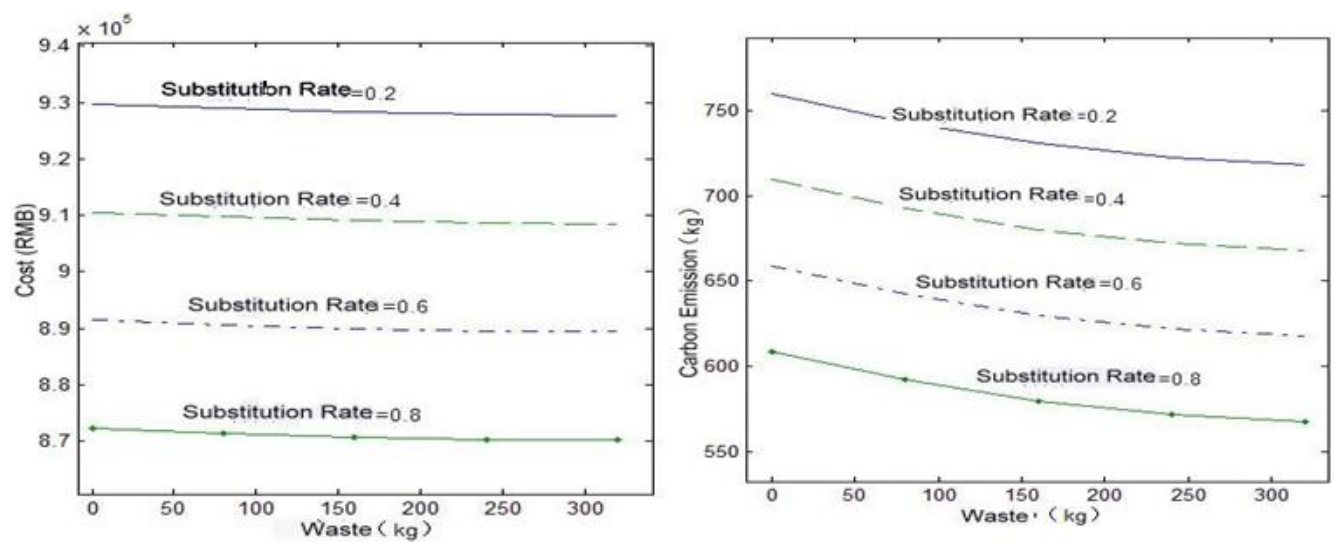

Figure 3. The Pareto Boundaries with Different Cost Substitute Rates

Additionally, there is positive relation between carbon emission and cost. In setting up remanufacturing network, economic cost comes mostly from freight, fixed cost of facilities and operation cost of remanufacturing. As carbon emission generates mostly from transportation and remanufacturing, when they emit more carbon, the costs of freight and remanufacturing increase accordingly, and finally the total economic cost increases.

Given different return rate (recovery rate $=0.5$, cost substitute rate $=0.8$ ) and recovery rate (recovery rate $=0.8$, substitute rate $=0.8$ ), we can get the result showed in Figure 4 and 5 . The Pareto Boundary of economic cost and waste generation is flatter comparing with that of carbon emission, and this is because there are a great number of fixed costs in economic cost. 
We can find out, the increase of cost substitute rate, return rate and recovery rate can shift the Pareto Boundary inward, which means the realization of Pareto improvement and win-win situation between profitability and environmental impact.
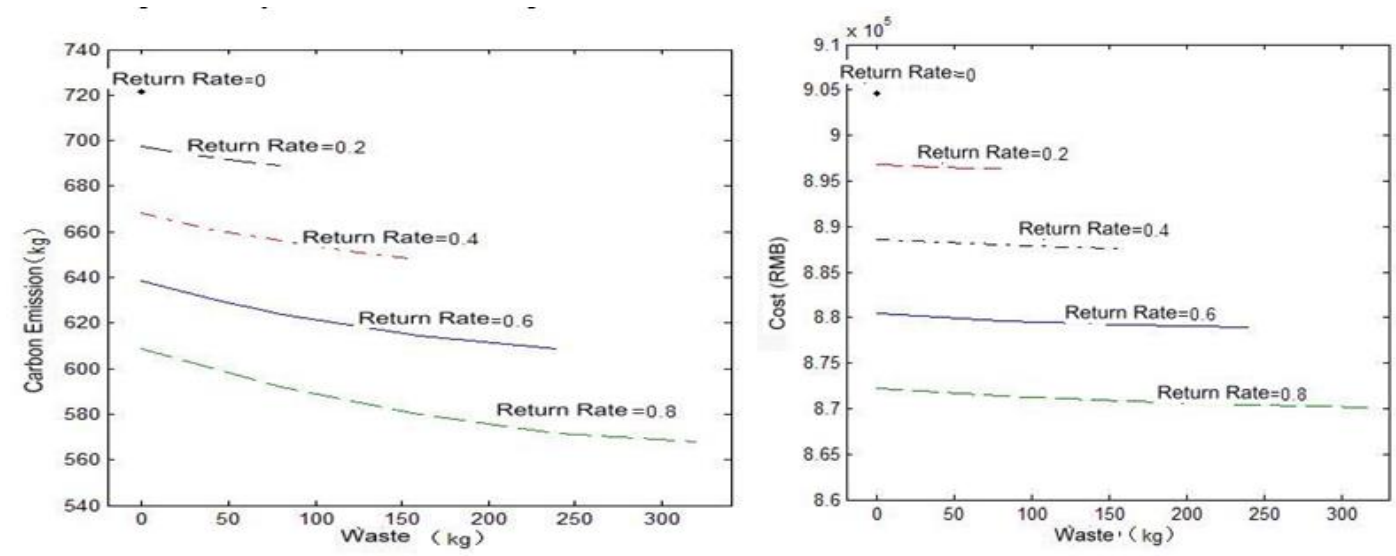

Figure 4. The Pareto Boundaries with Different Return Rates
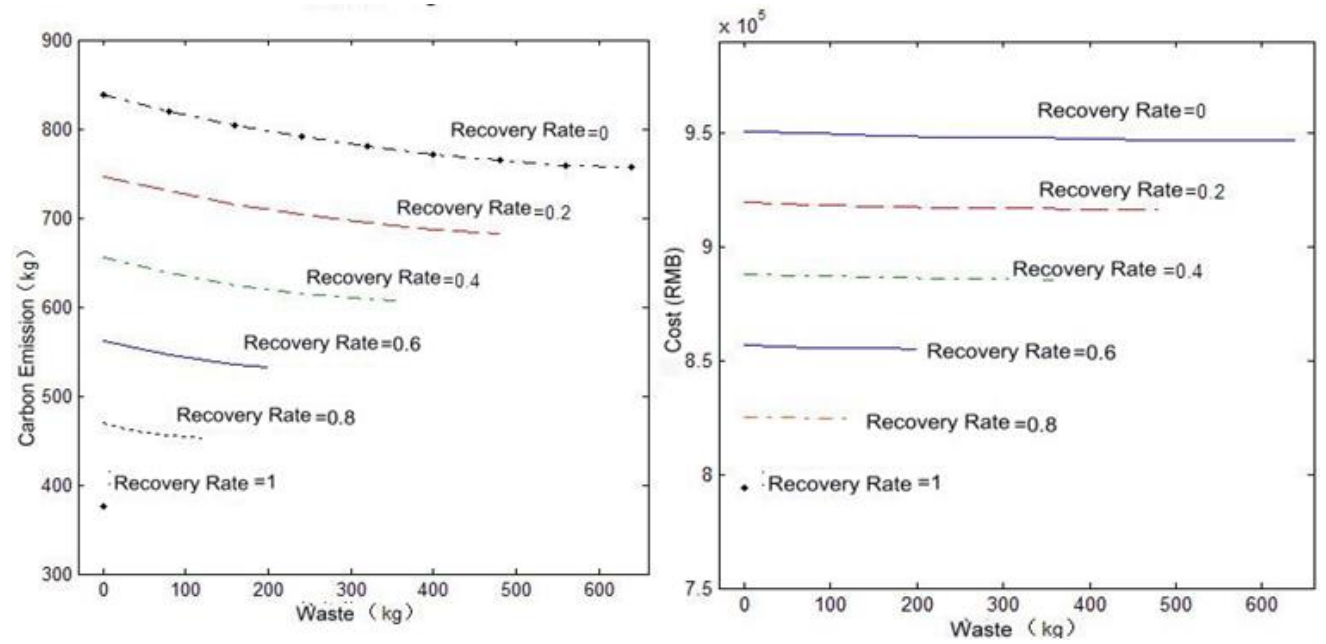

Figure 5. The Pareto Boundaries with Different Recovery Rates

\subsection{The Pareto Boundary with Equal Carbon Emission}

To meet the need of low-carbon economy, enterprises are supposed to trade off profitability and environmental impact on the premise of controlling the carbon emission. We can achieve the basis for decision-making by solving the Pareto curve with equal carbon emission offered in this model. Similar to the first algorithm, we can set the carbon emission as $T_{2}^{c}$ to be the constraint to get the following algorithm:

Step 1. Compute $\bar{T}_{3}:=\max \left\{T_{3} \mid T_{2}=T_{2}^{c}\right\}$ and $\underline{T}_{3}:=\min \left\{T_{3} \mid T_{2}=T_{2}^{C}\right\}$; Set step size to be $\varepsilon:=\left(\bar{T}_{3}-\underline{T}_{3}\right) / n$, Set $k:=0$; In the Pareto Boundary the number of solutions is $\mathrm{n}+1$; 
Step 2. Compute $T_{1}^{k}=\min \left\{T_{1} \mid T_{3}^{k}=\underline{T}_{3}+k \varepsilon, T_{2}=T_{2}^{C}\right\} ; k:=k+1 ; ;\left.\right|^{k:=k+1 ;}$;

Step 3. If $k=n+1$, end the algorithm and output $T^{*}\left(T_{2}^{C}\right)=\left\{\left(T_{1}^{k}, T_{3}^{k}\right) \mid k=0,1, \ldots, n\right\}$; Otherwise, go back to Step 2.

By adopting the method mentioned above, we can work out a similar Pareto Boundary (shown in Figure 6). Table 2 is the location decision corresponded by each optimal solution on the Pareto Boundary.

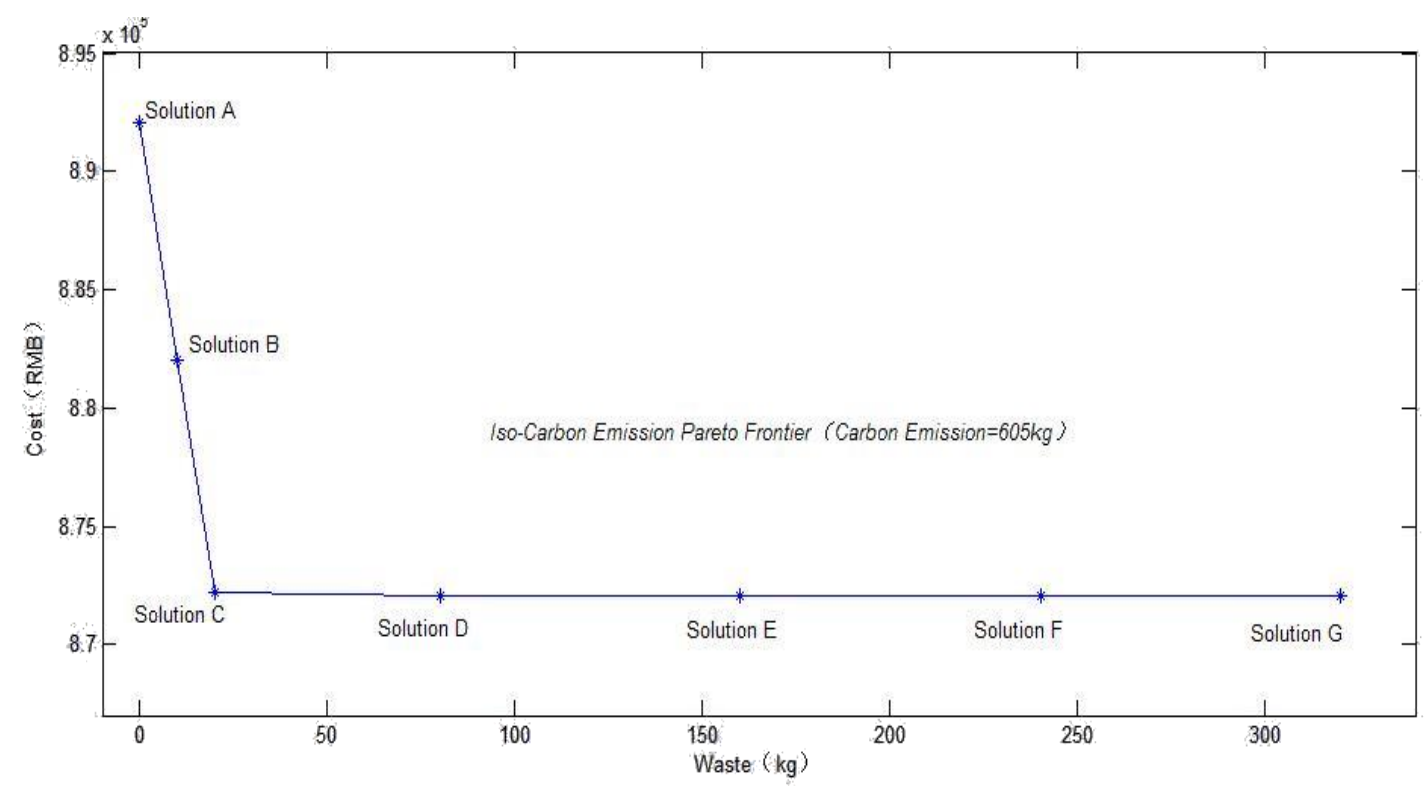

Figure 6. The Iso- $\mathrm{CO}_{2}$ Emission Pareto Boundary

In Figure 4, we can find out, although the solutions all fit Pareto optimal, there are still different site options. These solutions explain when environmental impact is more important, the facilities will be close to disposal facility and away from market and factories. When cost concerns more, the facilities will be away from disposal facility and close to market and factories. In order to save cost, some of the discarded products will not be even delivered to the disposal facility.

\begin{tabular}{|l|r|r|r|r|r|r|r|}
\hline Solutions & \multicolumn{1}{|c|}{ A } & \multicolumn{1}{|c|}{ B } & \multicolumn{1}{|c|}{ C } & D & \multicolumn{1}{|c|}{ E } & \multicolumn{1}{c|}{ G } \\
\hline Factory & 1,3 & 1,3 & 1,3 & 1,3 & 3,5 & 3,5 & 4,5 \\
\hline Distribution Center & $1,4,6$ & $3,4,6$ & $3,4,6$ & $3,4,6$ & $3,4,6$ & $3,4,6$ & $3,4,6$ \\
\hline Recycling Center & $1,2,4,5,6$ & $1,2,4,5,6$ & $1,2,4,5$ & $1,2,4,5$ & $1,2,4,5$ & $1,2,4,5$ & $1,2,4,5$ \\
\hline Waste (kg) & 0 & 10 & 20 & 80 & 160 & 240 & 320 \\
\hline Economic Cost (RMB) & 892020.5 & 882020.6 & 872220.4 & 872019.9 & 872019 & 872018.6 & 872018.4 \\
\hline
\end{tabular}

Table 4. Site-Selection Results in Pareto Solution Set 


\section{Conclusion and future work}

This paper aims to examine how to trade off the economic and ecological efficiency in the manufacturing-remanufacturing hybrid logistics network design in the context of low-carbon economy. To find out the optimal facility locations and materials flow allocation, a multiobjective mixed integer linear programming model is set up. Three minimizing targets are set in the objective function: economic cost, $\mathrm{CO}_{2}$ emission and waste generation. The finding of the paper shows that a Pareto improvement between economic and ecological efficiency could be obtained only by increasing either of the three of the critical rates (i.e. return rate, recovery rate, cost substitute rate).

An iso- $\mathrm{CO}_{2}$ emission curve is plotted to cater for the constraints from low-carbon economy, which can provide good practical implications to decision makers on how to trade off profitability and environmental impact and understand the relation of benefit deviation among the objectives. For example, decision-makers can have a series of optimal choices with the same $\mathrm{CO}_{2}$ emission but different cost and waste generation. Each choice may have different network design but all of these are Pareto optimal solutions, which provide a comprehensive evaluation of both economics and ecology for the decision making. As this solution is simply and clear in visual, this research may contribute to make the decision more scientific.

There are several limitations of this study that offer opportunities for future research. First, this paper introduces a model for a single product in a single closed-loop with limited capacity. In further research, the extension of this mode is suggested to fit it to multi-product and multi-loop situations. Second, only the design of manufacturing/remanufacturing hybrid network with certain parameters is discussed in this paper. During further research, the design with variant parameters could be discussed (i.e. under random environment, fuzzy environment and random and fuzzy mixed environment). Last but not the least, since remanufacturing practices have just started up in China, few enterprises really practice the closed-loop supply chain. Although we haven't adopted real statistics from enterprises in China in this research, some case-studies or even empirical studies on real statistics to verify this model will be possible in further research.

\section{Acknowledgements}

This research is funded by The Fundamental Research Funds for the Central Universities of China, Beijing Jiaotong Development Research Center. 


\section{References}

Bloemhof-Ruwaard, J. (1996). An Environmental Life Cycle Optimization Model for the European Pulp and Paper Industry. Omega, International Journal of Management Science, 24, 615-629. http://dx.doi.org/10.1016/S0305-0483(96)00026-6

Easwarana, G., \& Üsterb, H. (2010). A closed-loop supply chain network design problem with integrated forward and reverse channel decisions. IIE Transactions, 42(11), 779-792. http://dx.doi.org/10.1080/0740817X.2010.504689

Fang, S.J. (2010). Low-carbon Development in the Context of the Green Economy. Chinese Journal of Population, Resource and Environment, 20(4), 8-11.

Francasa, D., \& Minner, S. (2009). Manufacturing network configuration in supply chains with product recovery. Omega, 37, 757-769. http://dx.doi.org/10.1016/j.omega.2008.07.007

Krikke, H., Blemhof Ruwaard, J., \& Wassenhove, L.N. (2003). Concurrent Product and Closedloop Supply Chain Design with an Application to Refrigerators. International Journal of Production Economics, 41(16), 3689-3719. http://dx.doi.org/10.1080/0020754031000120087

Ma, Z.J., \& Dai, Y. (2005). Integrated Network Optimization Design Model in Manufacturing/Remanufacturing Hybrid System. Computer Integrated Manufacturing System, $11,1151-1157$.

Neto Fronta, J.Q, Bloemhof-Ruwaard, J.M., Van Nunen, J., \& Van Heck, E. (2008). Designing and Evaluating Sustainable Logistics Networks. International Journal of Production Economics, 111, 195-208. http://dx.doi.org/10.1016/j.ijpe.2006.10.014

Neto Fronta, J.Q., Walther, G., Bloemhof-Ruwaard, J.M., van Nunen, J.A.E.E., Spengler, T. (2009). A Methodology for Assessing Eco-efficiency in Logistics Networks. European Journal of Operational Research, 193, 670-682. http://dx.doi.org/10.1016/j.ejor.2007.06.056

Sasse, H., Karl, U., \& Renz, O. (1999). Cost Efficient and Ecological Design of Crosscompany Recycling Systems Applied to Sewage Sludge Re-integration. In D.K. Despotis and C. Zouponidis (Eds.). Proceedings of DSI conference, Athens, 3-4, 1418-1420.

Umeda, Y., Nonomura, A., \& Tomiyama, T. (2000). Study on Life-cycle Design for The Post Mass Production Paradigm. AIEDAM (Artificial Intelligence for Engineering Design, Analysis and Manufacturing), 14, 149-161. http://dx.doi.org/10.1017/S0890060400142040

Xie, J.P., Zhao, Zh. \& Ren, Y. (2008). Review of the Recovery and Remanufacturing Planning for Discarded Products. Chinese Journal of Management, 5(2), 305-310. 
Xu, B.X. (2011). The Dilemma of and Solution to Eco Efficiency under Low Carbon Economy. Journal of Dalian University of Technology, 2, 12-16.

\section{Appendix}

\begin{tabular}{|l|l|l|}
\hline Notation & Meaning & Note \\
\hline$f$ & manufacturing/remanufacturing factory & $f=\left\{\mathrm{f}_{1}, \mathrm{f} 2, \ldots, \mathrm{F}\right\}$ \\
\hline$w$ & distribution center & $w=\left\{w_{1}, w 2, \ldots, W\right\}$ \\
\hline$r$ & recycling center & $r=\left\{r_{1}, r_{2}, \ldots, R\right\}$ \\
\hline$s$ & distribution/recycling center & $s=\{s 1, s 2, \ldots, S\}$ \\
\hline$c$ & the market & $c=\{c 1, c 2, \ldots, C\}$ \\
\hline$d$ & disposal facility & $d=\left\{d_{1}, d 2, \ldots, D\right\}$ \\
\hline$i$ & potential distribution center & $i \in I=\{1,2, \ldots, I\}$ \\
\hline$j$ & potential recycling center & $j \in J=\{1,2, \ldots, J\}$ \\
\hline$T_{k}$ & optimization objectives & $k=1,2,3$ \\
\hline
\end{tabular}

Table 5. otations

\begin{tabular}{|c|c|c|}
\hline Type & Decision variables & Meaning \\
\hline \multirow{3}{*}{$\begin{array}{l}\text { Location } \\
\text { decision } \\
\text { variables }\end{array}$} & $Y_{m}^{f}$ & whether building factory in $\mathrm{m}$ \\
\hline & $Y_{i}^{w}$ & whether building distribution center in î \\
\hline & $Y_{j}^{r}$ & whether building recycling center in $\mathrm{j}$ \\
\hline \multirow{5}{*}{$\begin{array}{l}\text { Materials } \\
\text { flow } \\
\text { allocation }\end{array}$} & $X_{m i}$ & $\begin{array}{l}\text { the amount of products delivered from factory } \mathrm{m} \text { to distribution } \\
\text { center }\end{array}$ \\
\hline & $X_{\dot{i}}$ & products delivered from distribution center i to market c \\
\hline & $X_{c j}$ & products delivered from market $\mathrm{c}$ to recycling center $\mathrm{j}$ \\
\hline & $X_{j m}$ & products delivered from recycling center $\mathrm{j}$ to factory $\mathrm{m}$ \\
\hline & $X_{j d}$ & products delivered from recycling center $\mathrm{j}$ to disposal facility $\mathrm{d}$ \\
\hline
\end{tabular}

Table 6. Decision variables in the model 


\begin{tabular}{|c|c|c|}
\hline Type & Parameter & Meaning \\
\hline $\begin{array}{l}\text { Market } \\
\text { demand }\end{array}$ & $D_{c}$ & demand of market $\mathrm{c}$ \\
\hline \multirow{3}{*}{ Capacity } & $A_{m}^{f}$ & capacity available at factory in $\mathrm{m}$ \\
\hline & $A_{i}^{w}$ & maximum capacity of the distribution center in $\mathrm{j}$ \\
\hline & $A_{j}^{r}$ & maximum capacity of the recycling center in $\mathrm{j}$ \\
\hline \multirow{9}{*}{ Cost } & $F_{m}^{f}$ & fixed cost of factory establishment in $\mathrm{m}$ \\
\hline & $F_{i}^{w}$ & fixed cost of distribution center establishment in i \\
\hline & $F_{j}^{r}$ & fixed cost of recycling center establishment in $\mathrm{j}$ \\
\hline & $C_{m i}$ & Cost per unit of each unit from factory $\mathrm{m}$ to distribution center $\mathrm{i}$ \\
\hline & $C_{i c}$ & Cost for transportation per unit from distribution center i to market c \\
\hline & $C_{c j}$ & Cost for transportation per unit from market c to recycling center j \\
\hline & $C_{j d}$ & $\begin{array}{l}\text { Cost for transportation per unit from recycling center } \mathrm{j} \text { to disposal } \\
\text { facility d }\end{array}$ \\
\hline & $C_{j m}$ & Cost for transportation per unit from recycling center $\mathrm{j}$ to factory $\mathrm{m}$ \\
\hline & $C_{p_{p}}$ & Cost of manufacturing one product \\
\hline \multirow{7}{*}{$\begin{array}{l}\text { Carbon } \\
\text { emission }\end{array}$} & $E_{m i}$ & $\begin{array}{l}\text { Carbon emitted during the transportation from factory } m \text { to distribution } \\
\text { centeri per unit }\end{array}$ \\
\hline & $E_{i c}$ & $\begin{array}{l}\text { Carbon emitted during the transportation from distribution center i to } \\
\text { market c per unit }\end{array}$ \\
\hline & $E_{c j}$ & $\begin{array}{l}\text { Carbon emitted during the transportation from market } \mathrm{c} \text { to recycling } \\
\text { centerj per unit }\end{array}$ \\
\hline & $E_{j d}$ & $\begin{array}{l}\text { Carbon emitted during the transportation from recycling center } \mathrm{j} \text { to } \\
\text { disposal facility d per unit }\end{array}$ \\
\hline & $E_{j m}$ & $\begin{array}{l}\text { Carbon emitted during the transportation from recycling center } \mathrm{j} \text { to } \\
\text { factory } \mathrm{m} \text { per unit }\end{array}$ \\
\hline & $E_{p}$ & Carbon emitted when manufacturing each new product \\
\hline & $E_{r}$ & Carbon emission cut by remanufacturing each product \\
\hline \multirow{3}{*}{$\begin{array}{l}\text { Recovery } \\
\text { rate }\end{array}$} & $\delta_{c}$ & return rate of products in market c \\
\hline & $\beta$ & $\begin{array}{l}\text { Recovery rate, the ratio of recoverable products to collected discarded } \\
\text { ones }\end{array}$ \\
\hline & $\gamma$ & $\begin{array}{l}\text { cost substitution rate, which shows the ratio of the cost saved by } \\
\text { remanufacturing to manufacturing, } 0 \leq \gamma \leq 1, C_{r}=\gamma C_{p}, E_{r}=\gamma E_{p}\end{array}$ \\
\hline
\end{tabular}

Table 7. Parameters in the model

Journal of Industrial Engineering and Management, 2013 (www.jiem.org)

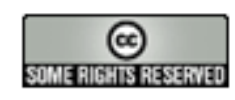

El artículo está con Reconocimiento-NoComercial 3.0 de Creative Commons. Puede copiarlo, distribuirlo y comunicarlo públicamente siempre que cite a su autor y a Intangible Capital. No lo utilice para fines comerciales. La licencia completa se puede consultar en http://creativecommons.org/licenses/by-nc/3.0/es/ 